\title{
Chloroquine exerts antitumor effects on NB4 acute promyelocytic leukemia cells and functions synergistically with arsenic trioxide
}

\author{
SHOUSHENG LIU ${ }^{1 *}$, XIUYU CAI $^{1 *}$, LIANGPING XIA ${ }^{1}$, CHANG JIANG $^{1}$, \\ PING $\mathrm{CHEN}^{1}$, XIAOPAI WANG ${ }^{2}$, BEI ZHANG ${ }^{1}$ and $\mathrm{HONG} \mathrm{YUN}_{\mathrm{ZHAO}}^{3}$ \\ ${ }^{1}$ Department of General Medicine, Sun Yat-sen University Cancer Center, State Key Laboratory of Oncology in South China, \\ Collaborative Innovation Center for Cancer Medicine, Guangzhou, Guangdong 510060; ${ }^{2}$ Department of Pathology, \\ Guangzhou First People's Hospital, Guangzhou, Guangdong 510080; ${ }^{3}$ Department of Medical Oncology, \\ Sun Yat-sen University Cancer Center, State Key Laboratory of Oncology in South China, \\ Collaborative Innovation Center for Cancer Medicine, Guangzhou, Guangdong 510060, P.R. China
}

Received January 12, 2017; Accepted October 26, 2017

DOI: $10.3892 / \mathrm{ol} .2017 .7488$

\begin{abstract}
Chloroquine (CQ) has been confirmed to exhibit antitumor effects on different types of cancer cell, but whether it exerts the same effect on acute promyelocytic leukemia (APL) cells remains to be confirmed. In the present study, the effects of various concentrations of CQ on the growth, apoptosis and cell cycle distribution of NB4 cells, as well as the potential mechanisms underlying these effects, were examined. The combined effect of CQ and arsenic trioxide (ATO) on the growth of NB4 cells was also determined. The results of the present study demonstrated that CQ treatment inhibited cell proliferation, and induced mitochondrial pathway apoptosis and $\mathrm{S}$ phase arrest in a dose-dependent manner by regulating apoptosis- and cell cycle-related proteins. CQ and ATO had a synergistic effect on the growth inhibition of NB4 cells, which may have been induced through the inhibition of autophagy. In conclusion, the results of the present study indicated that CQ exhibits a cytotoxic effect on NB4
\end{abstract}

Correspondence to: Dr Hong Yun Zhao, Department of Medical Oncology, Sun Yat-sen University Cancer Center, State Key Laboratory of Oncology in South China, Collaborative Innovation Center for Cancer Medicine, 651 Dongfeng East Road, Guangzhou, Guangdong 510060, P.R. China

E-mail: zhaohongy@yeah.net

Dr Bei Zhang, Department of General Medicine, Sun Yat-sen University Cancer Center, State Key Laboratory of Oncology in South China, Collaborative Innovation Center for Cancer Medicine, 651 Dongfeng East Road, Guangzhou, Guangdong 510060, P.R. China

E-mail: zhangbei@sysucc.org.cn

*Contributed equally

Key words: chloroquine, arsenic trioxide, apoptosis, cell cycle, autophagy cells and has a synergistic effect when combined with ATO, which thereby improves the curative effect of ATO on APL.

\section{Introduction}

Chloroquine (CQ) is an effective and well-tolerated drug for the treatment of malaria (1), and is also a useful agent for the treatment of systemic lupus erythematosus and rheumatoid arthritis due to its anti-inflammatory properties $(2,3)$. Recently, a number of studies demonstrated that CQ exhibits antitumor activity in different types of cancer cells, including human liver cancer, gallbladder carcinoma, breast cancer and colon cancer cells (4-6), and that it is less toxic to non-tumor cells than standard chemotherapy agents (7). However, whether or not CQ exerts the same effect on acute promyelocytic leukemia (APL) cells remains unknown.

Autophagy is an intracellular degradation process that eliminates damaged organelles or proteins through lysosomal activity (8). Autophagy serves an important role in homeostasis under conditions of cellular stress, including nutrient limitation, hypoxia and chemotherapy (9). A number of diseases, including cancer, are associated with dysregulated autophagy processes (10-12). However, the role of autophagy in tumors is very complex and is suggested to have both pro-death and pro-survival effects in different types of cancer (13). As tumor cells proliferate rapidly, the relative deficiency of nutrients and oxygen shifts the metabolic pathway of cancer cells from aerobic oxidation towards glycolysis (14), and autophagy may serve as an alternative source of energy for cancer cell survival (15). However, autophagy also leads to programmed cell death, which may induce anticancer effects (16). A previous study demonstrated that high basal autophagy levels were a potential mechanism of resistance to cell death in APL cell lines (17), indicating that autophagy promotes survival and that autophagy inhibition may serve an antitumor role in APL cells.

CQ is an inhibitor of late-stage autophagy, which takes effect after autophagosomes have already formed $(18,19)$. Based on the results of the aforementioned studies, we hypothesized that CQ may inhibit autophagy and exert anticancer effects on APL NB4 cells. 
Arsenic trioxide (ATO) is an anticancer drug used for the treatment of APL. However, ATO also induces autophagy in APL cells, which may weaken its antitumor activity (20). The addition of CQ may compensate for this defect to enhance the effect of ATO. In the present study, the effect of CQ on the growth, apoptosis and cell cycle distribution of NB4 cells was investigated. In addition, the combined effect of CQ and ATO on the growth of NB4 cells was also determined.

\section{Materials and methods}

Cell lines, cell culture and reagents. NB4 cells were obtained from the Third Affiliated Hospital of Sun Yat-sen University (Guangzhou, China). The cells were maintained in RPMI-1640 medium containing $10 \%$ fetal bovine serum (both from Gibco; Thermo Fisher Scientific, Inc., Waltham, MA, USA) in a $37^{\circ} \mathrm{C}$ incubator containing 5\% $\mathrm{CO}_{2}$. CQ and ATO were purchased from Sigma-Aldrich; Merck KGaA (Darmstadt, Germany). CQ was prepared as a $0.1 \mathrm{M}$ stock solution in dimethyl sulfoxide. ATO stock solution was made at a concentration of $1 \mathrm{mM}$ with normal saline. Stock solutions were diluted to working concentrations for use.

Cell proliferation assay. The cytotoxicity of CQ and ATO on NB4 cells was determined using an MTS assay (Promega Corporation, Madison, WI, USA), as previously described (21). A total of $10^{4} \mathrm{NB} 4$ cells were cultured in each well of a 96-well plate and were treated with various concentrations of CQ for 48 or $72 \mathrm{~h}$. Than $20 \mu \mathrm{l}$ MTS was added and the absorbance at $490 \mathrm{~nm}$ was measured using a microplate reader (Thermo Fisher Scientific, Inc.) after a 3 -h incubation. The inhibition rate of cell proliferation was calculated using the following formula: [1 - (OD of experimental well/OD of control)] x 100\%.

The potential synergy between CQ and ATO was evaluated according to the following formula (21):

$$
Q=\frac{E_{(C Q+A T O)}}{E_{(C Q)}+E_{(A T O)}-E_{(C Q)} * E_{(A T O)}}
$$

Where $E_{(\mathrm{CQ}+\mathrm{ATO})}, E_{(\mathrm{CQ})}$ and $E_{(\mathrm{ATO})}$ are the inhibition rates of the combination treatment, CQ monotherapy and ATO monotherapy, respectively. $Q<0.85$ indicates antagonism, $0.85 \leq \mathrm{Q} \leq 1.15$ indicates additive effects and Q $>1.15$ indicates synergy. Briefly, $1 \times 10^{4}$ NB4 cells were seeded into each well of a 96-well plate and were treated with various concentrations of CQ and ATO. The combined effect was evaluated by calculating the $\mathrm{Q}$ values of each treatment at 48 and $72 \mathrm{~h}$.

Apoptosis assay. The rate of apoptosis in NB4 cells was determined using the Annexin V-fluorescein isothiocyanate (FITC)/propidium iodide (PI) apoptosis kit (BD Biosciences, Franklin Lakes, NJ, USA) according to the manufacturer's instructions. Following a $48 \mathrm{~h}$ incubation with CQ, the cells were harvested and washed twice with PBS, prior to being incubated with $5 \mu \mathrm{l}$ Annexin V-FITC and $5 \mu \mathrm{l}$ PI for $10 \mathrm{~min}$ in the dark at room temperature. Analysis of the cell apoptotic rate was performed using a flow cytometer (FC 500; Beckman Coulter, Inc., Brea, CA, USA) with CellQuest Pro software program (version 5.1; BD Biosciences). The early

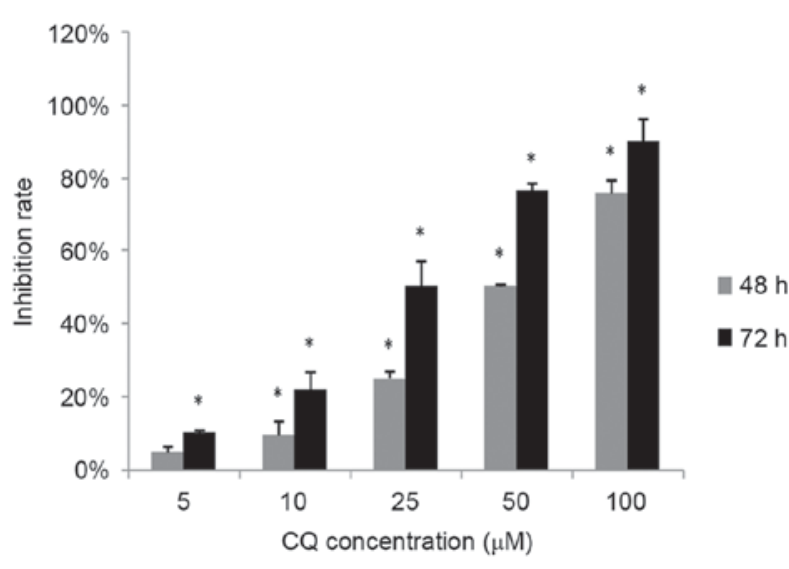

Figure 1. CQ inhibits NB4 cell proliferation in vitro. NB4 cells were treated with CQ at various concentrations. After 48 and $72 \mathrm{~h}$ of incubation, cell viability was analyzed using an MTS assay. The data are presented as the mean \pm standard deviation of 6 separate experiments. ${ }^{*} \mathrm{P}<0.05$ compared with the $0 \mu \mathrm{M}$ control group at the corresponding time-points.

apoptotic (Annexin V-FITC-positive, PI-negative) and late apoptotic (Annexin V-FITC-positive, PI-positive) cells were quantified.

Cell cycle analysis. Following a $48 \mathrm{~h}$ incubation with CQ, cells were harvested, washed twice with cold PBS and fixed in cold $70 \%$ ethanol at $4^{\circ} \mathrm{C}$ for $24 \mathrm{~h}$. The cells were then centrifuged at a speed of $1,000 \mathrm{x} \mathrm{g}$ at $4^{\circ} \mathrm{C}$ for $5 \mathrm{~min}$. The fixed cells were resuspended in PBS containing $50 \mathrm{mg} / \mathrm{ml} \mathrm{PI,} 100 \mathrm{mg} / \mathrm{ml}$ RNase and $0.2 \%$ Triton X-100 (both from Sigma-Aldrich; Merck $\mathrm{KGaA}$ ) at $37^{\circ} \mathrm{C}$ for $15 \mathrm{~min}$. The cell cycle profiles of the treated cells were subsequently analyzed using a flow cytometer (Beckman Coulter, Inc.). The percentage of cells in each phase of the cell cycle was determined using Modfit LT software (version 3.2; Verity Software House, Inc., Topsham, ME, USA).

Western blot analysis. After $48 \mathrm{~h}$ of incubation with CQ, ATO or CQ+ATO, the cells were collected and the total cell lysates were prepared with cell lysis buffer (Beyotime Institute of Biotechnology, Haimen, China). Western blot analysis was performed as previously described (21), using rabbit monoclonal antibodies against B-cell lymphoma 2 (Bcl-2; cat. no. 2872S), Bcl-2-like protein X (Bax; cat. no. 5023S), Bcl-2-like protein 11 (Bim; cat. no. 2933S), myeloid cell leukemia 1 (Mcl-1; cat. no. 39224S), cleaved caspase-9 (cat. no. 20750S), cleaved caspase-3 (cat. no. 9661S), cell division cycle 25A (CDC25A) (cat. no. 3652S), cyclin-dependent kinase 2 (CDK2) (cat. no. 2546S), cyclin A, light chain 3B (LC3B; cat. no. 2775S), p62 (cat. no. 39749S) and GAPDH (cat. no. 2118S) (all diluted to 1:1,000; Cell Signaling Technology, Inc., Danvers, MA, USA), followed by incubation with a IRDye ${ }^{\circledR} 680$ RD conjugated goat anti-rabbit IgG secondary antibody (1:20,000, cat. no. P/N 926-68071; LI-COR Biosciences, Lincoln, NE, USA) at room temperature for $2 \mathrm{~h}$ in the dark. The bands were then detected using the Odyssey ${ }^{\circledR}$ CLx Infrared Imaging System (LI-COR Biosciences).

Statistical analysis. The data are presented as the mean \pm standard deviation. Comparison between two groups 
(A)
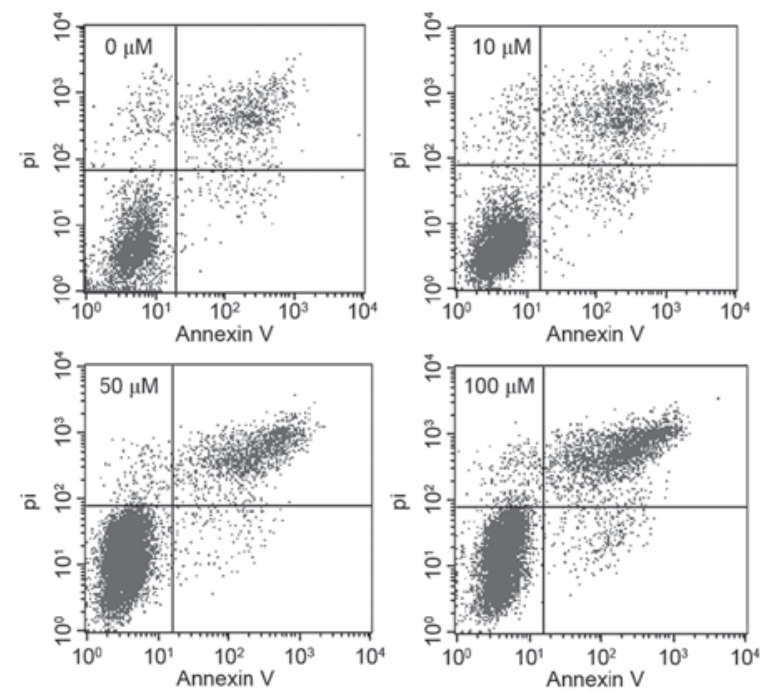

(C)

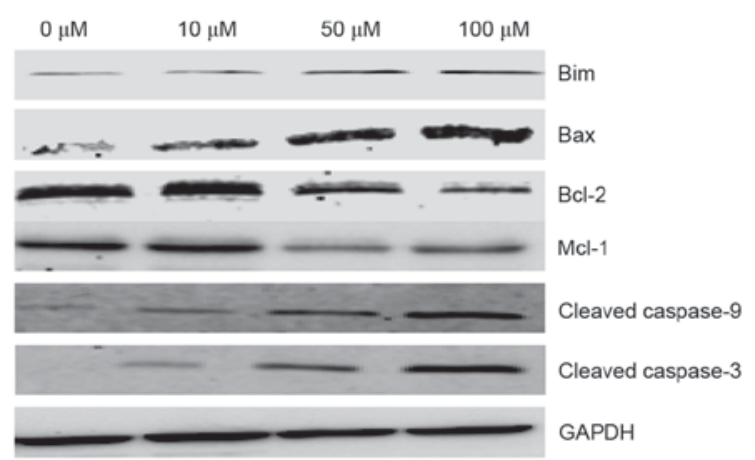

(B)

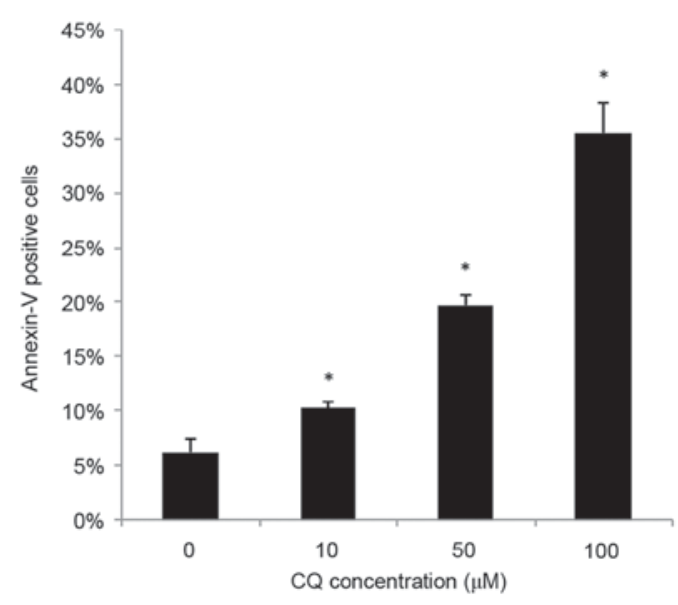

(D)

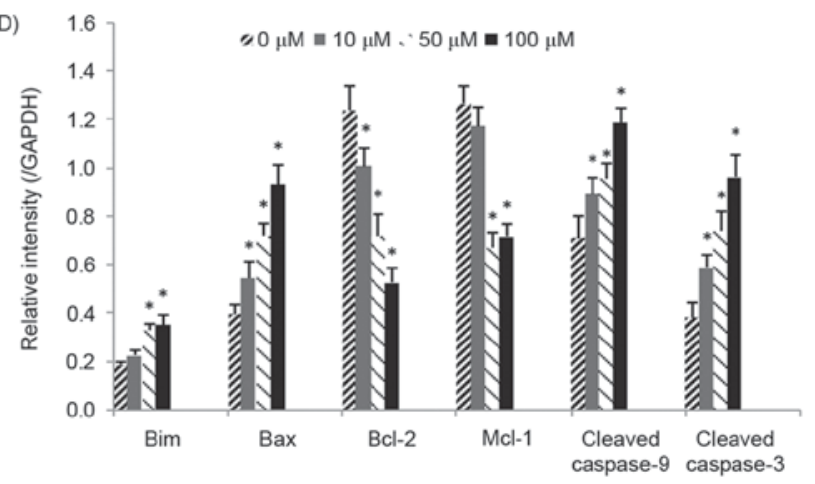

Figure 2. Apoptosis of NB4 cells induced by CQ. (A) Cells were incubated with increasing concentrations of CQ for 48 h and Annexin V/PI staining was used to analyze apoptosis. A representative experiment is presented. (B) Annexin V-positive cells, indicative of early and late apoptosis. Results are presented as the mean \pm standard deviation of 3 separate experiments. (C) The expression of apoptosis-associated proteins following treatment with various concentrations of $\mathrm{CQ}$ was determined by western blot analysis. (D) Quantification of the western blot analysis. * $\mathrm{P}<0.05$ compared with the $0 \mu \mathrm{M}$ control group. CQ, chloroquine; PI, propidium iodide.

was performed using a two-tailed Student's t-test, and pairwise multiple comparisons among the groups were performed using a one-way analysis of variance test together with the Student-Newman-Keuls method with SPSS 16.0 software (SPSS, Inc., Chicago, IL, USA). P<0.05 was considered to indicate a statistically significant difference.

\section{Results}

$C Q$ inhibits the proliferation of NB4 cells. The inhibitory effect of CQ on NB4 cell proliferation was measured using an MTS assay. NB4 cells were exposed to 0, 5, 10, 25, 50 and $100 \mu \mathrm{M}$ CQ for 48 and $72 \mathrm{~h}$, respectively, followed by an MTS assay. As demonstrated in Fig. 1, the proliferation of NB4 cells decreased significantly with CQ treatment in a time- and dose-dependent manner $(\mathrm{P}<0.05)$. The highest inhibition rates observed were $75.88 \pm 3.5 \%$ at $48 \mathrm{~h}$ and $90.32 \pm 5.89 \%$ at $72 \mathrm{~h}$ at a concentration of $100 \mu \mathrm{M}$ CQ.

$C Q$ induces apoptosis in NB4 cells. Next, the role of apoptosis in the antitumor activity of CQ was assessed. NB4 cells that had been exposed to CQ for $48 \mathrm{~h}$ were collected for the apoptosis assay. As demonstrated in Fig. 2A and B, $\mathrm{CQ}$ treatment caused a significant increase in the rate of apoptosis $(\mathrm{P}<0.05)$, particularly in the rate of late apoptosis, in a dose-dependent manner. The highest proportion of apoptotic (Annexin V-positive) cells was $35.51 \pm 2.79 \%$ at $100 \mu \mathrm{M}$.

To further explore the underlying mechanisms of CQ-induced apoptosis, the effect of CQ on the expression of apoptosis-related proteins was investigated. Increasing concentrations of CQ upregulated the level of cleaved caspase-3, thereby confirming CQ-induced apoptosis. The pro-apoptotic proteins Bax, Bim and cleaved caspase-9 were significantly upregulated, whereas the anti-apoptotic proteins Bcl-2 and Mcl-1 were significantly downregulated in the CQ-treated groups in a dose-dependent manner $(\mathrm{P}<0.05$; Fig. 2C and D).

CQ induces NB4 cell S phase arrest. The influence of CQ on cell cycle progression was examined in order to illustrate another potential mechanism of its anti-proliferative activity. The effects of various concentrations of CQ on the cell cycle distribution in NB4 cells were determined. As demonstrated in Fig. 3A and B, the population of cells in the $\mathrm{S}$ phase was significantly increased $(\mathrm{P}<0.05)$, whereas the number of cells in the $G_{0} / G_{1}$ phase was reduced, following $C Q$ treatment, in a concentration-dependent manner. Treatment of NB4 cells with 

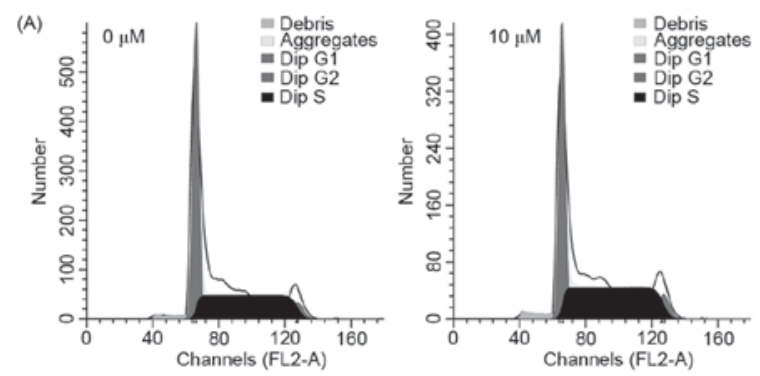

(B)
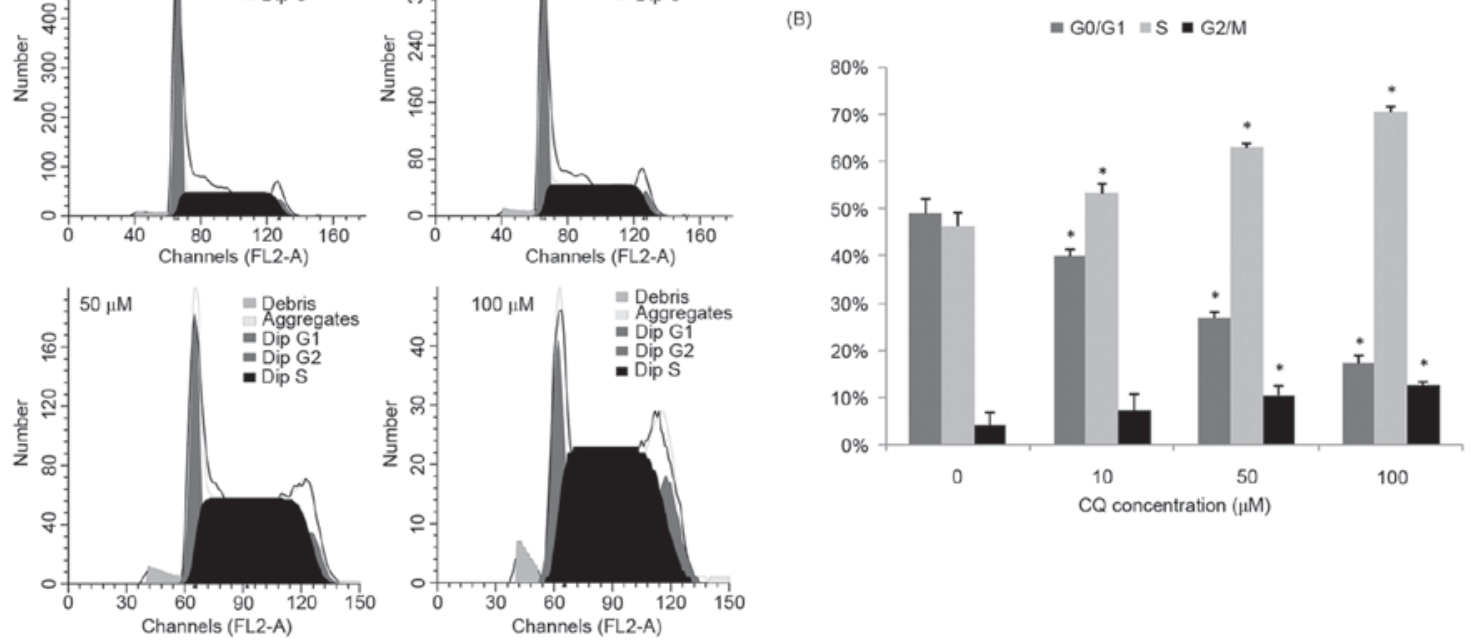

(C)
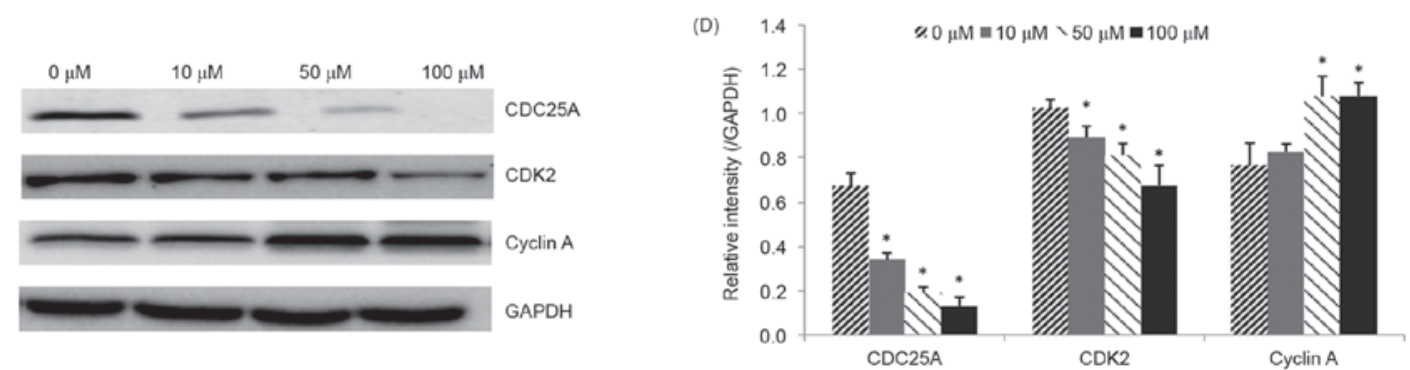

Figure 3. Cell cycle distribution of NB4 cells following treatment with CQ. (A) Cells were treated with increasing concentrations of CQ for $48 \mathrm{~h}$ followed by cell cycle analysis using a flow cytometer. A representative experiment is presented. (B) Quantification of the flow cytometry results. The results are presented as the mean \pm standard deviation of 3 separate experiments. (C) The expression level of cell cycle-associated proteins, including CDC25A, CDK2 and cyclin A, was determined by western blot analysis. (D) Quantification of the western blot analysis. "P $<0.05$ compared with the $0 \mu \mathrm{M}$ control group. CQ, chloroquine; CDC25A, cell division cycle 25A; CDK, cyclin-dependent kinase.

$100 \mu \mathrm{M}$ CQ resulted in a significant increase in the percentage of cells in the $\mathrm{S}$ phase, from $46.20 \pm 2.86 \%$ (at $0 \mu \mathrm{M})$ to $70.43 \pm 1.17 \%(\mathrm{P}<0.05)$.

Since CQ was observed to arrest NB4 cells in the S phase, western blot analysis was subsequently performed in order to evaluate its effect on $\mathrm{S}$ phase cell cycle regulators, including CDC25A, CDK2 and cyclin A. The results presented in Fig. 3C and D demonstrate that CDC25A and CDK2 were downregulated, whereas cyclin A was upregulated, following CQ treatment, in a dose-dependent manner.

$C Q$ synergizes with ATO in inhibiting the growth of NB4 cells. As ATO is a typical drug for the treatment of APL, the combined effect of CQ and ATO was subsequently examined. NB4 cells were exposed to $1 \mu \mathrm{M}$ ATO and 10 or $25 \mu \mathrm{M}$ CQ simultaneously for 48 or $72 \mathrm{~h}$. Jin's modified Burgi's formula was used to evaluate the combined effect of ATO and CQ. There was a significant increase in the inhibition rate in the combined treatment groups $(\mathrm{P}<0.05$; Fig. 4). As demonstrated in Fig. 4, the Q values were all $>1.15$ at 48 and $72 \mathrm{~h}$, indicating a synergistic effect between the two drugs in inhibiting cell proliferation.

$C Q$ regulates $A T O$-induced autophagy. LC3 and p62 were detected as markers for autophagy using western blot analysis. As demonstrated in Fig. 5A and B, the level of LC3-II

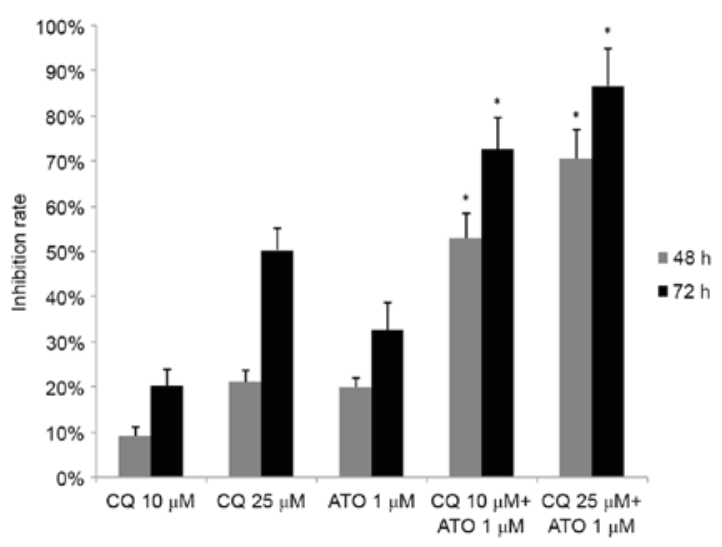

Figure 4. The combined effect of CQ and ATO on the growth inhibition of NB4 cells. NB4 cells were incubated with 10 or $25 \mu \mathrm{M}$ CQ and $1 \mu \mathrm{M}$ ATO simultaneously for $48 \mathrm{~h}$, and the combined effect was assessed by Jin's modified Burgi's formula. The data are presented as the mean \pm standard deviation of 6 repeated experiments. ${ }^{*} \mathrm{P}<0.05$ vs. single CQ or ATO group. $\mathrm{CQ}$, chloroquine; ATO, arsenic trioxide.

was increased, and p62 was decreased, following treatment with ATO alone, indicating that ATO induced autophagy in NB4 cells. CQ upregulated LC3-II and p62 levels, confirming that $\mathrm{CQ}$ inhibited autophagy in its later phase. A significant increase in LC3-II and a moderate increase in p62 were observed in the combined treatment group $(\mathrm{P}<0.05)$, 

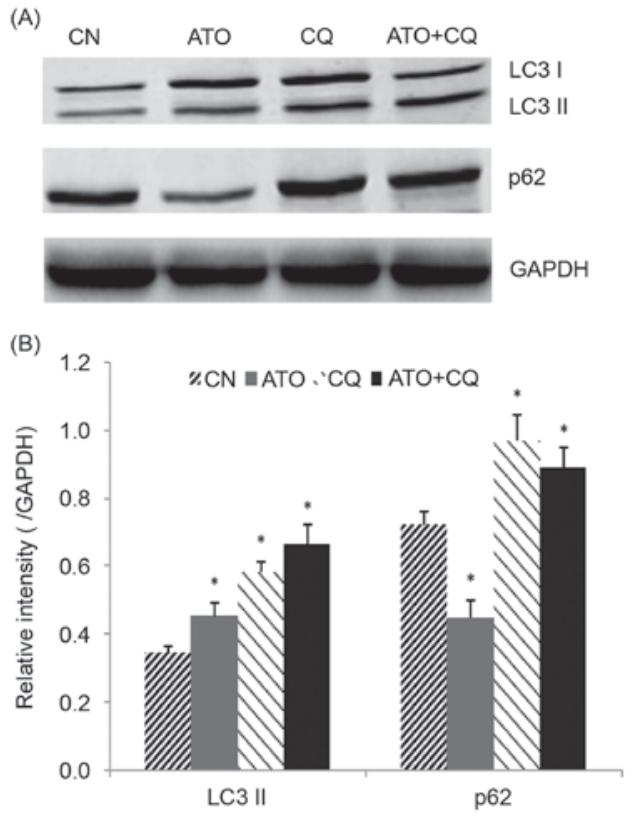

Figure 5. The effect of ATO and CQ treatments on the expression of autophagy-associated proteins. (A) Protein extracts of the NB4 cells were analyzed for LC3-II and p62 expression by western blotting. (B) Quantification of the western blotting. ${ }^{*} \mathrm{P}<0.05$ compared with the control group. ATO, arsenic trioxide; CQ, chloroquine; LC-II, light chain II; CN, control.

indicating that CQ inhibited the ATO-induced autophagy in NB4 cells.

\section{Discussion}

CQ exerts antitumor effects on a variety of cancer cells; however, whether it has the same effect on the NB4 APL cell line remains unknown. Therefore, the present study was designed to explore the effect of CQ on NB4 cells. The present study indicated that CQ has a potent antitumor effect and functions synergistically with ATO in NB4 cells.

Previous studies have demonstrated that the potential mechanisms for the antitumor effects of CQ may include the inhibition of autophagy (22), the induction of apoptosis $(23,24)$, the elimination of cancer stem cells (25), the normalization of vasculature (26), the enhancement of the immune response (27) and the arrest of cell cycle progression (22). The focus of the present study was primarily on the apoptosis, cell cycle distribution and autophagy induced by CQ treatment. CQ treatment was revealed to induce apoptosis, to upregulate the pro-apoptosis proteins Bax and Bim, and to downregulate the anti-apoptosis proteins $\mathrm{Bcl}-2$ and $\mathrm{Mcl}-1$ in a dose-dependent manner. Furthermore, the expression of cleaved caspase-9, an important component of the intrinsic mitochondrial pathway, was also increased. These data are consistent with the results of previous studies $(24,28)$. Based on these data, we hypothesized that the mitochondrial apoptotic pathway and members of the Bcl-2 family are involved in the CQ-induced apoptosis of NB4 cells.

CQ has been reported to induce cell cycle alterations in cancer cells, but the specific results have varied for different types of cancer; $C Q$ has been demonstrated to cause $\mathrm{G}_{2} / \mathrm{M}$ cell cycle arrest in breast cancer cells (29), $\mathrm{G}_{0} / \mathrm{G}_{1}$ cell cycle arrest in liver cancer cells (28), $\mathrm{S}$ phase arrest in choriocarcinoma cells (30) and no obvious change in colon cancer cells (22). The inconsistency in cell cycle alterations may be due to the intrinsic differences between the tumor cell lines. In the present study, CQ treatment induced a significant increase in the number of cells in the $\mathrm{S}$ phase and a decrease in the number of cells in the $G_{0} / G_{1}$ phase in a concentration-dependent manner. $\mathrm{S}$ phase arrest accompanied with a decrease in the number of cells in $G_{0} / G_{1}$ phase following treatment with antitumor drugs has also been reported in a number of other studies (31-33), and does not appear to affect the antitumor effect of these drugs. One potential explanation for this is that the inhibition of cell proliferation is associated with cell cycle arrest, but the phase at which the cells are arrested depends on the anticancer drugs and the antitumor cells involved. Tumor cell proliferation relies on the progression from one cell cycle phase to the next; on the introduction of antitumor drugs, the cell cycle progression is disrupted. In the present study, a relatively high number of cells had progressed from the $\mathrm{G}_{0} / \mathrm{G}_{1}$ phase to the $\mathrm{S}$ phase, whereas relatively fewer cells had progressed from the $S$ phase to the $\mathrm{G}_{2} / \mathrm{M}$ phase, thereby indicating that the cell cycle was blocked at the $\mathrm{S}$ phase. The normal growth process was disrupted and cell proliferation was partly suppressed.

Cell cycle regulatory proteins, including cyclins and CDKs, are considered to serve an important role in cell cycle progression (34). Cyclin A, CDK2 and CDC25A are critical factors associated with the $\mathrm{S}$ phase of the cell cycle (35). CDC25A may activate $\mathrm{CDK} 2$, which in turn leads to the activation of the cyclin-CDK complex and causes cell cycle progression $(36,37)$. The present study demonstrated that CQ reduced the expression of CDC25A and CDK2, and increased the expression of cyclin A. It was deduced that CQ downregulated CDC25A, suppressing the activation of $\mathrm{CDK} 2$, which therefore decreased the formation of the cyclin A-CDK2 complex. The reduced formation of the cyclin-CDK complex arrested the NB4 cells in the $\mathrm{S}$ phase. Furthermore, the increased expression of cyclin A may result from the reduced formation of the cyclin-CDK complex.

Despite being a frequently used anticancer agent in APL, ATO may also induce unwanted or fatal side effects, including differentiation syndrome, QT interval prolongation, hepatotoxicity, the incidence of secondary malignancies and damage to the nervous system $(38,39)$. In the present study, CQ functioned synergistically with ATO, indicating that a lower dose of ATO is required to achieve the same curative effect when combined with $\mathrm{CQ}$, therefore reducing the risks associated with ATO. As mentioned previously, autophagy may promote survival in NB4 cells (17). CQ, a widely used autophagy inhibitor, was also confirmed to effectively inhibit the late phase of autophagy in the present study, which may be a possible explanation for the antitumor effect of CQ on NB4 cells. A previous study demonstrated that ATO induces autophagy in NB4 cells and that the suppression of autophagy may enhance its effect (40). In the present study, the level of autophagy induced by ATO was significantly reduced when used in combination with CQ in NB4 cells, which may explain why CQ functioned synergistically with ATO. Another potential reason for this synergy is that the 
two drugs exhibit different effects on cell cycle distribution, with CQ inducing $\mathrm{S}$ phase arrest, and ATO inducing $\mathrm{G}_{2} / \mathrm{M}$ phase arrest (41).

Taken together, the results of the present study demonstrated that CQ effectively suppressed the growth of NB4 cells by inducing apoptosis, inducing $\mathrm{S}$ phase arrest and inhibiting autophagy. Furthermore, CQ appears to function synergistically with ATO, indicating that the combined use of CQ and ATO maybe a promising approach for future APL therapy. However, the true potential of this treatment option requires further investigation.

\section{Acknowledgements}

The present study was funded by the Medical Science and Technology Research Foundation of Guangdong Province (grant no. A2016181) and the Natural Science Foundation of Guangdong Province (grant no. 2017A030310337).

\section{References}

1. Solomon VR and Lee H: Chloroquine and its analogs: A new promise of an old drug for effective and safe cancer therapies. Eur J Pharmacol 625: 220-233, 2009.

2. Augustijns P, Geusens P and Verbeke N: Chloroquine levels in blood during chronic treatment of patients with rheumatoid arthritis. Eur J Clin Pharmacol 42: 429-433, 1992.

3. Bezerra EL, Vilar MJ, da Trindade Neto PB and Sato EI: Double-blind, randomized, controlled clinical trial of clofazimine compared with chloroquine in patients with systemic lupus erythematosus. Arthritis Rheum 52 : 3073-3078, 2005.

4. Liang X, Tang J, Liang Y, Jin R and Cai X: Suppression of autophagy by chloroquine sensitizes 5-fluorouracil-mediated cell death in gallbladder carcinoma cells. Cell Biosci 4: 10, 2014.

5. Chen P, Hu T, Liang Y, Jiang Y, Pan Y, Li C, Zhang P, Wei D, Li P, Jeong LS, et al: Synergistic inhibition of autophagy and neddylation pathways as a novel therapeutic approach for targeting liver cancer. Oncotarget 6: 9002-9017, 2015.

6. Mei L, Chen Y, Wang Z, Wang J, Wan J, Yu C, Liu X and Li W: Synergistic anti-tumour effects of tetrandrine and chloroquine combination therapy in human cancer: A potential antagonistic role for p21. Br J Pharmacol 172: 2232-2245, 2015.

7. Rahim R and Strobl JS: Hydroxychloroquine, chloroquine, and all-trans retinoic acid regulate growth, survival, and histone acetylation in breast cancer cells. Anticancer Drugs 20: 736-745, 2009.

8. Lin NY, Beyer C, Giessl A, Kireva T, Scholtysek C, Uderhardt S, Munoz LE, Dees C, Distler A, Wirtz S, et al: Autophagy regulates $\mathrm{TNF} \alpha$-mediated joint destruction in experimental arthritis. Ann Rheum Dis 72: 761-768, 2013.

9. Yuan HX, Russell RC and Guan KL: Regulation of PIK3C3/VPS34 complexes by MTOR in nutrient stress-induced autophagy. Autophagy 9: 1983-1995, 2013.

10. Choi AM, Ryter SW and Levine B: Autophagy in human health and disease. N Engl J Med 368: 1845-1846, 2013.

11. Galluzzi L, Pietrocola F, Bravo-San Pedro JM, Amaravadi RK, Baehrecke EH, Cecconi F, Codogno P, Debnath J, Gewirtz DA, Karantza V, et al: Autophagy in malignant transformation and cancer progression. EMBO J 34: 856-880, 2015.

12. White E: The role for autophagy in cancer. J Clin Invest 125: 42-46, 2015

13. Liu LL, Long ZJ, Wang LX, Zheng FM, Fang ZG, Yan M, Xu DF, Chen JJ, Wang SW, Lin DJ and Liu Q: Inhibition of mTOR pathway sensitizes acute myeloid leukemia cells to aurora inhibitors by suppression of glycolytic metabolism. Mol Cancer Res 11: 1326-1336, 2013.

14. Vander Heiden MG, Cantley LC and Thompson CB: Understanding the Warburg effect: The metabolic requirements of cell proliferation. Science 324: 1029-1033, 2009.
15. Chiavarina B, Whitaker-Menezes D, Migneco G, Martinez-Outschoorn UE, Pavlides S, Howell A, Tanowitz HB, Casimiro MC, Wang C, Pestell RG, et al: HIF1-alpha functions as a tumor promoter in cancer associated fibroblasts, and as a tumor suppressor in breast cancer cells: Autophagy drives compartment-specific oncogenesis. Cell Cycle 9: 3534-3551, 2010.

16. Morselli E, Galluzzi L, Kepp O, Mariño G, Michaud M, Vitale I, Maiuri MC and Kroemer G: Oncosuppressive functions of autophagy. Antioxid Redox Signal 14: 2251-2269, 2011.

17. Gañán-Gómez I, Estañ-Omaña MC, Sancho P, Aller P and Boyano-Adánez MC: Mechanisms of resistance to apoptosis in the human acute promyelocytic leukemia cell line NB4. Ann Hematol 94: 379-392, 2015.

18. Amaravadi RK and Thompson CB: The roles of therapy-induced autophagy and necrosis in cancer treatment. Clin Cancer Res 13: 7271-7279, 2007.

19. Tasdemir E, Galluzzi L, Maiuri MC, Criollo A, Vitale I, Hangen E, Modjtahedi N and Kroemer G: Methods for assessing autophagy and autophagic cell death. Methods Mol Biol 445: 29-76, 2008.

20. Fan Y, Chen M, Meng J, Yu L, Tu Y, Wan L, Fang K and Zhu W: Arsenic trioxide and resveratrol show synergistic anti-leukemia activity and neutralized cardiotoxicity. PLoS One 9: e105890, 2014.

21. Liu SS, Wang XP, Li XB, Liang JY, Liu LL, Lu Y, Zhong XY and Chen YX: Zoledronic acid exerts antitumor effects in NB4 acute promyelocytic leukemia cells by inducing apoptosis and $\mathrm{S}$ phase arrest. Biomed Pharmacother 68: 1031-1036, 2014.

22. Choi JH, Yoon JS, Won YW, Park BB and Lee YY: Chloroquine enhances the chemotherapeutic activity of 5-fluorouracil in a colon cancer cell line via cell cycle alteration. APMIS 120: 597-604, 2012.

23. Zheng Y, Zhao YL, Deng X, Yang S, Mao Y, Li Z, Jiang P, Zhao X and Wei Y: Chloroquine inhibits colon cancer cell growth in vitro and tumor growth in vivo via induction of apoptosis. Cancer Invest 27: 286-292, 2009.

24. Jiang PD, Zhao YL, Deng XQ, Mao YQ, Shi W, Tang QQ, Li ZG, Zheng YZ, Yang SY and Wei YQ: Antitumor and antimetastatic activities of chloroquine diphosphate in a murine model of breast cancer. Biomed Pharmacother 64: 609-614, 2010.

25. Choi DS, Blanco E, Kim YS, Rodriguez AA, Zhao H, Huang TH, Chen CL, Jin G, Landis MD, Burey LA, et al: Chloroquine eliminates cancer stem cells through deregulation of Jak2 and DNMT1. Stem Cells 32: 2309-2323, 2014.

26. Maes H, Kuchnio A, Peric A, Moens S, Nys K, De Bock K, Quaegebeur A, Schoors S, Georgiadou M, Wouters J, et al: Tumor vessel normalization by chloroquine independent of autophagy. Cancer Cell 26: 190-206, 2014.

27. Ratikan JA, Sayre JW and Schaue D: Chloroquine engages the immune system to eradicate irradiated breast tumors in mice. Int J Radiat Oncol Biol Phys 87: 761-768, 2013.

28. Hu T, Li P, Luo Z, Chen X, Zhang J, Wang C, Chen P and Dong Z: Chloroquine inhibits hepatocellular carcinoma cell growth in vitro and in vivo. Oncol Rep 35: 43-49, 2016.

29. Jiang PD, Zhao YL, Shi W, Deng XQ, Xie G, Mao YQ, Li ZG, Zheng YZ, Yang SY and Wei YQ: Cell growth inhibition, $\mathrm{G} 2 / \mathrm{M}$ cell cycle arrest, and apoptosis induced by chloroquine in human breast cancer cell line Bcap-37. Cell Physiol Biochem 22: 431-440, 2008.

30. Nilkaeo A, Bhuvanath S, Praputbut S and Wisessombat S: Induction of cell cycle arrest and apoptosis in JAR trophoblast by antimalarial drugs. Biomed Res 27: 131-137, 2006.

31. Romani AA, Desenzani S, Morganti MM, La Monica S, Borghetti AF and Soliani P: Zoledronic acid determines S-phase arrest but fails to induce apoptosis in cholangiocarcinoma cells. Biochem Pharmacol 78: 133-141, 2009.

32. Ohnuki H, Izumi K, Terada M, Saito T, Kato H, Suzuki A, Kawano Y, Nozawa-Inoue K, Takagi R and Maeda T: Zoledronic acid induces $\mathrm{S}$-phase arrest via a DNA damage response in normal human oral keratinocytes. Arch Oral Biol 57: 906-917, 2012.

33. Tan H, Gao S, Zhuang Y, Dong Y, Guan WH, Zhang K, Xu J and Cui J: R-Phycoerythrin induces SGC-7901 apoptosis by arresting cell cycle at S phase. Mar Drugs 14: E166, 2016.

34. Hsu YL, Uen YH, Chen Y, Liang HL and Kuo PL: Tricetin, a dietary flavonoid, inhibits proliferation of human breast adenocarcinoma mcf-7 cells by blocking cell cycle progression and inducing apoptosis. J Agric Food Chem 57: 8688-8695, 2009. 
35. Vermeulen K, Van Bockstaele DR and Berneman ZN: The cell cycle: A review of regulation, deregulation and therapeutic targets in cancer. Cell Prolif 36: 131-149, 2003.

36. George Rosenker KM, Paquette WD, Johnston PA, Sharlow ER, Vogt A, Bakan A, Lazo JS and Wipf P: Synthesis and biological evaluation of 3-aminoisoquinolin-1(2H)-one based inhibitors of the dual-specificity phosphatase Cdc25B. Bioorg Med Chem 23: 2810-2818, 2015

37. Tilaoui M, Mouse HA, Jaafari A and Zyad A: Differential effect of artemisinin against cancer cell lines. Nat Prod Bioprospect 4 189-196, 2014.

38. Au WY, Kumana CR, Lam CW, Cheng VC, Shek TW, Chan EY, Liu R and Kwong YL: Solid tumors subsequent to arsenic trioxide treatment for acute promyelocytic leukemia. Leuk Res 31: 105-108, 2007.
39. Ghavamzadeh A, Alimoghaddam K, Rostami S, Ghaffari SH, Jahani M, Iravani M, Mousavi SA, Bahar B and Jalili M: Phase II study of single-agent arsenic trioxide for the front-line therapy of acute promyelocytic leukemia. J Clin Oncol 29: 2753-2757, 2011.

40. Ren Y, Xie Y, Chai L, Wang S and Cheng M: Autophagy modification augmented the treatment effects initiated by arsenic trioxide in NB4 cells. Med Oncol 28: 231-236, 2011.

41. Li Y, Qu X, Qu J, Zhang Y, Liu J, Teng Y, Hu X, Hou K and Liu Y: Arsenic trioxide induces apoptosis and G2/M phase arrest by inducing $\mathrm{Cbl}$ to inhibit PI3K/Akt signaling and thereby regulate p53 activation. Cancer Lett 284: 208-215, 2009. 